\title{
A longevidade dos elementos da forma urbana
}

\author{
Flavia Ribeiro Botechia \\ Prefeitura Municipal de Vitória, Rua Vitório Nunes da Motta, 220, Enseada do Suá, \\ Vitória, Espírito Santo, 29050-330, Brasil. E-mail: flaviabotechia@ gmail.com
}

Artigo revisto recebido a 11 de Janeiro de 2018

\begin{abstract}
Resumo. Este artigo, que deriva de capítulo da tese de doutorado, foi organizado em duas partes. A primeira correspondeu ao entendimento da noção de processos morfológicos, tendo como fio condutor o trabalho desenvolvido por M. R. G. Conzen, que considerou, pelo menos, as ações de transformação, adição, adaptação e estagnação. Na segunda parte, motivada pela pesquisa de doutorado, maior atenção foi dada ao processo de estagnação com ênfase na persistência dos elementos urbanos, incluindo os estudos dessa natureza sobre as cidades europeias, latino-americanas e o estudo de caso desenvolvido na tese. O que se pretendeu verificar, com a pesquisa bibliográfica, foi a recolha de subsídios teóricos e práticos para o estudo da persistência da rua considerando uma cidade ordinária, existente, ativa, onde o processo de transformação é contínuo, dando-se por ação material, humana ou do tempo sem interferências externas excepcionais.
\end{abstract}

Palavras-chave: morfologia urbana, processos morfológicos, persistência, rua

\section{Introdução}

'O espaço todo é salpicado - constelado, infestado - de pequenas chamas que parecem vaga-lumes, exatamente como aqueles que as pessoas do campo, nas belas noites de verão, veem esvoaçar, aqui e ali, ao acaso de seu esplendor, discreto, passante, tremeluzente (...)' (Didi-Huberman, 2011, p. 11).

Autores como Morris (1979), Kostof (1991), Portas (2005), Dias Coelho (2014) se opõem à noção de cidade como obra acabada. Com essa perspetiva, contribuem para o entendimento de que, no tecido urbano coexistem diferentes elementos da forma, produzidos em tempos distintos e com ciclos de vida autônomos. Essa autonomia incorre numa dessincronização elementar e se relaciona com, pelo menos, dois processos morfológicos (Conzen, 1960): o de contínua transformação, como o que acontece mais frequentemente com edificações e usos; e outro que lida com a estagnação das estruturas, principalmente, no que se refere ao traçado e ao parcelamento fundiário.

A evidência de que a forma é resultado de acúmulo de tempos, constitui a base de entendimento da cidade estratificada em camadas e produzida gradualmente por sobreposições, adições, apagamentos. E é o que, também, proporciona uma leitura em que passado e presente não estão tão distantes assim. Lado a lado, sobrepostos, justapostos, apagados, transformados, intrincados, variados elementos, de diferentes tempos, juntos constituem a cidade e tornam o traçado urbano um híbrido de temporalidades e formas.

Ao observar nas cidades vestígios materiais de épocas anteriores, aponta-se a existência de edifícios, catedrais, edificações ordinárias; porém, não se deve esquecer de que os elementos bidimensionais também possuem níveis de perenidade. É assim que um caminho primitivo pode ser a forma pretérita do eixo de uma rodovia; canais de irrigação ou drenagem, a forma inicial de 
vias urbanas; tramas agrícolas, a origem de limites de lotes ou quarteirões. A perspetiva da investigação sobre as transformações físicas, sozinha, não abrange toda a complexidade da metamorfose formal.

Este artigo, que deriva de capítulo de tese de doutorado (sob orientação de Maria Isabel Villac), está organizado em duas partes. A primeira corresponde ao entendimento da noção de processos morfológicos, tendo como fio condutor o trabalho desenvolvido pelo geógrafo M.R.G. Conzen, considerando, pelo menos, os processos de transformação, adição, adaptação e estagnação. Na segunda parte, apresenta-se em detalhe um fragmento da pesquisa realizada especificamente sobre o processo de estagnação, dando maior atenção à persistência dos elementos urbanos, incluindo os estudos dessa natureza sobre as cidades europeias, latino-americanas e o estudo de caso desenvolvido na tese.

\section{Processos morfológicos}

Para Conzen, a metamorfose formal não reflete apenas as condições sociais, econômicas, intelectuais de determinadas épocas, mas também as formas antecedentes determinam em maior ou menor grau as estruturas que lhe são posteriores.

Reconhece-se, com isso, que na formação dos traçados coexistem diferentes processos que incidem sobre a forma, posto que ao mesmo tempo em que ocorrem transformações, há elementos urbanos que oferecem grande resistência às mudanças, como é o caso da rua: ' (...) o elemento mais refratário da planta da cidade' (Conzen, 1960, p. 7). Com esta reflexão, o referido autor observou e categorizou a metamorfose da planta da cidade, no tempo, identificando a existência de, pelo menos, quatro processos morfológicos (morphological processes) principais - transformação, adição, adaptação e estagnação - definidos, de modo geral, como:

Any casual sequence that leads to the definition or alteration of any townscape feature(s) and/or their mutual composition. In Britain context, for example, six morphological processes have general importance, the first two additive, the later four transformative: accretionary growth, fringe belt formation, building repletion, building replacement, plot pattern metamorphosis, and central commercial redevelopment (Conzen, 2004).

Nos estudos sobre o caso britânico, Conzen identifica quatro processos transformativos: '(...) a superocupação da edificação, a substituição da edificação, a metamorfose do padrão de lotes e a renovação do centro comercial' (Glossário de termos técnicos, traduzido por Pereira Costa e Gimmler Neto, 2015). Ainda mais especificamente sobre o estudo do 'ciclo da parcela burguesa' (burgage cycle), nota-se a consequência do grande interesse do autor pela relação transformativa entre as parcelas e a implantação dos edifícios, que consiste na progressiva construção no afastamento de fundos chegando a fases subsequentes de ocupação quase completa do lote, ruína e demolição (voltando o lote a ficar vazio) Figura 1.

Sobre o processo da adição, Conzen reconhece uma sequência de atividades como crescimento acumulativo e cintura periférica (fringe belts) - Figura 2. A maior diferença entre o processo transformativo e o de adição é que o primeiro opera por sobreposição; e o último, por justaposição. Como contribuição, Dias Coelho (2013), ao analisar o caso português, entende que os tecidos se transformam pelo processo de adição porque respondem a demandas de expansão do núcleo urbano, motivadas por intenções de natureza política ou econômica. $\mathrm{Na}$ identificação deste processo, o autor reconhece três variantes: a adição de elementos ao tecido preexistente; a extensão de um traçado; a justaposição de traçados antigos e novos, ou mesmo dois novos com padrões diferentes.

$\mathrm{O}$ ato de construir sobre o construído não implica somente ações contínuas e sucessivas. Ao sobrepor uma nova camada, poderá ocorrer um caso específico: a adaptação elementar. A forma preexistente, então, condiciona a nova forma e até a deforma. Dias Coelho (2014, p. 25), em suas investigações, especificou casos em que o agente público (ou privado), para promover uma reestruturação urbana, utiliza-se do ato de substituir, rasgar tecidos existentes, demolir edificações, adaptar: '(...) reinterpretando-o e sobrepondo-lhe, de um 


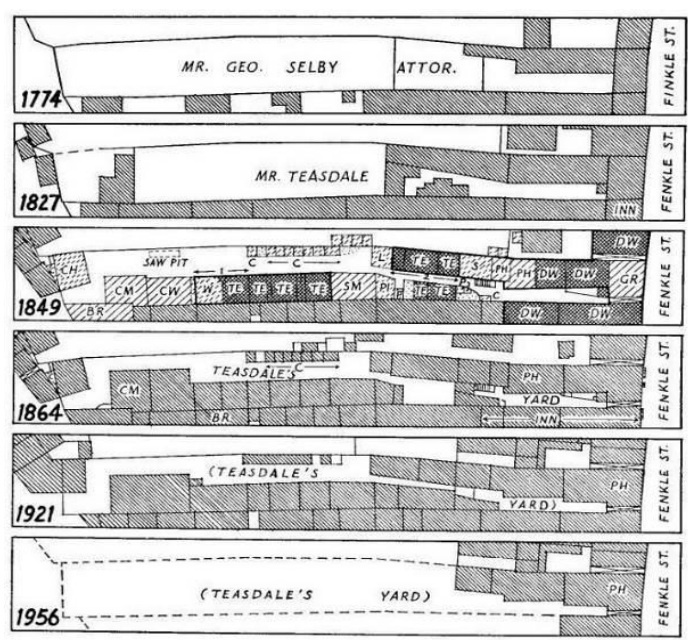

Figura 1. Estudo sobre o ciclo da parcela burguesa entre 1774 e 1956 (fonte: Conzen, 1960).

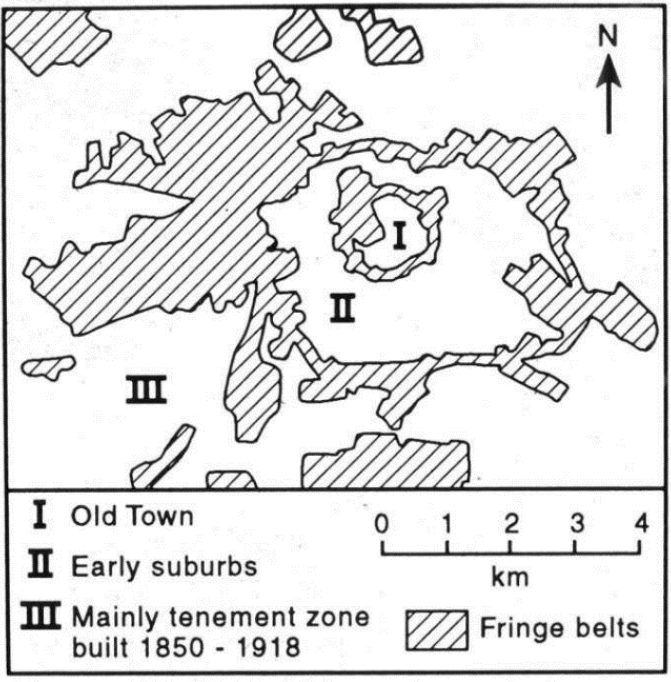

Figura 2. Identificação de cinturas periféricas (fringe belts) um dos processos morfológicos de adição (fonte: Conzen, 1960).

modo singular ou de conjunto, uma ordem urbana de hierarquia superior. A sobreposição realiza-se por impossibilidade prática e material de substituir integralmente um tecido e, através da distribuição de elementos urbanos pontuais, permite a alteração da importância e da relação entre elementos preexistentes'.

$\mathrm{O}$ quarto processo considera a permanência e persistência dos elementos na longa duração. Se as estruturas são cíclicas e há uma relação de transformação dessincronizada entre os elementos urbanos; e se há ações de adição, sobreposição e/ou sedimentação dos tecidos e traçados urbanos, também se torna ponderado considerar, como uma das etapas do ciclo de vida de cada elemento urbano, a estagnação.

Ao definir o termo 'systematic differentiated persistence of forms (principle of)', Conzen afirma que a planta urbana é, dentre outras formas da paisagem, aquela com maior gradação de persistência ao longo do tempo:

Generally speaking, a gradation exits in the relative persistence through time of the three form complexes of townscape. The town plan is the most persistent, followed by the building fabric, while land and building is the least persistent. The town plan is slow to change because of its corporately sanctioned purpose from early times and the long sequence of broadly conformal investment of fixed capital both private and public. The building fabric also tends towards persistence for similar reasons but is liable to accidental destruction by fire, conflagration or war and to piecemeal replacement through change of ownership or changed functional requirements - through buildings generally have had a greater capacity for adaptation to changing needs. The pattern of land and building utilization, however, responds most readily to new functional impulses. It has accommodated the modern diversification of activities in retail and other central services, together with the progressive separation of business from residential functions, all within a stock of largely traditional buildings types sited within an ever older through somewhat modified plot pattern (Conzen, 2004, Apêndice A).

Alguns termos podem ser associados ao estudo do processo de estagnação elementar, tais como inércia, permanência, persistência, termos estes que não devem ser tratados como sinônimos. Do mesmo modo, alguns autores também podem ser vinculados com o estudo das formas antigas e duradouras.

\section{O processo da estagnação}

Lavedan (1926), Conzen (1960) e Pinon (2008) tornaram-se, no desenvolvimento da pesquisa, referencial teórico fundamental 
para entendimento do processo morfológico da estagnação, mais especificamente da persistência (que envolve um nível de deformação da forma inicial), ao se deterem sobre o estudo de cidades europeias.

Lavedan é reconhecidamente um dos primeiros a fazer um estudo sistemático e aplicado sobre a persistência morfológica, identificando o que ele denominou loi de la persistence du plan (Lavedan, 1926). O autor testou o argumento de que as formas urbanas são transmitidas no tempo, ao fazer uma análise comparativa das plantas de seis cidades, identificando, nesta condução, traços de persistências: uma estrada no caso de Tell el Amarna, o plano da antiga cidade de Salonica, caminhos medievais de Fourvières, uma muralha medieval convertida no caminhamento das avenidas em Beaumont du Périgord, Cambridge, Paris e Munique. Ao fim dos estudos práticos, o autor concluiu com a formulação de uma lei 'não universal, nem absoluta', que explica por que a planta continua naturalmente no tempo (no caso das cidades que passaram por sucessivas transformações). Essa tese, segundo Grudet (2007), insere Lavedan junto a outros historiadores em um movimento que entendia a cidade como uma nova especialização no vasto campo da história, questionando o fato de que a História da Arte abrangia o estudo de 'uma igreja, um castelo, uma casa'. Mas, e a cidade? E seus espaços abertos e as ruas?

Conzen (1960), ao se deter sobre análises de pequenas cidades e vilas inglesas identificou a existência de processos morfológicos que agem sobre a substituição das formas urbanas, em três escalas: da planta da cidade, da edificação e do uso. Pelo menos dois verbetes do 'Glossário de termos técnicos', elaborado por este autor, fazem referência à temática: Persistence of inherited forms e Systematic differentiated persistence of forms (principle of). $\mathrm{Na}$ definição destes termos, Conzen afirma que o 'plano urbano' (composição bidimensional da planta da cidade) é dentre os elementos morfológicos aquele mais persistente e que a longevidade das formas urbanas está relacionada ao seu uso.

Pinon (2008), retomando a lei formulada por Lavedan com a publicação de Défense et illustration de la 'Loi de persistance du plan', identificou a persistência de fragmentos das camadas urbanas preexistentes no caso de estudo de cidades francesas de fundação romana. Fez isso defendendo como método de reconstituição da história da materialidade dos traçados, a prospecção retrospectiva por meio de fotografias aéreas, mapas cadastrais e análise morfológica. Entretanto, advertidamente afirmou (...) qu'une restitution n'est jamais qu'une hypothèse de travail (...) (Pinon, 2008, p. 132).

Procedendo à análise retrospectiva das plantas cadastrais, Pinon (2008) sistematizou as diferenças conceituais entre dois tipos específicos de estagnação: persistência e permanência (já tratadas por Lavedan, em 1926). Posto isso com referência às formas urbanas seria possível identificar, na análise documental cartográfica, indícios de que a forma atual da cidade é resultado de um processo de permanência (sedimentação) e persistência (deformação) de estruturas anteriores, sejam elas materiais, sejam mesmo imateriais.

$\mathrm{Na}$ América Latina, alguns autores procederam com investigações correlatas. Waisman, em ' $O$ interior da história: historiografia arquitetônica para uso de latino-americanos' (2013), com a convicção de que é preciso reformular (ou formular) instrumentos historiográficos para compreender e analisar os países não centrais destacou conceitos para o desenvolvimento de estudos históricos e prática arquitetônica. Em trecho específico do livro, a autora afirmou que a teorização sobre as temporalidades da história, de curta e longa duração, pode ser aplicada ao caso da cidade latino-americana, considerando tanto o campo das materialidades quanto o das ideias, visto que uma duração pode ser contínua ou sujeita a interrupções: 'Sob estes movimentos - aparecimentos e reaparecimentos, permanências relativas, acontecimentos súbitos - existiriam camadas da realidade arquitetônica que persistem durante tão longo tempo que subsistem sob as mudanças visíveis e podem constituir elementos de estabilidade ou mesmo de atraso na evolução' (Waisman, 2013, p. 73).

Ao tratar da inércia, dentre os conceitos listados aquele que mais se aproxima da noção de persistências, Waisman (2013) 
considerou que as observações feitas sobre as cidades europeias '(...) conservam, em parte, sua validade para nossas cidades'. No estudo, por exemplo, da trama na América Latina, é possível concluir que os lotes cadastrais não são invariáveis e a persistência se observa em tipologias (o pátio central, a casa chouriço, medianeiras, o claustro de determinadas ordens religiosas): 'A estrutura do lote, no entanto, continuará impondo suas leis à cidade em crescimento e, frequentemente, reproduzirá em altura o esquema primitivo de ocupação do solo (...)' (Waisman, 2013, p. 75).

Sobre as pesquisas realizadas no Brasil, pode-se destacar neste artigo como referências fundamentais os trabalhos de Reis (2004; 2014[1970]), Holanda (1994[1957]) e Abreu (2012), que embora não sejam autores específicos do campo da morfologia urbana, apontam questões para o debate sobre a materialidade das cidades.

Reis (2004), ao estudar as transformações da cidade de São Paulo, registrou informações sobre as estruturas variantes e invariantes. Fez uso de desenhos, plantas, mapas, fotografias para tratar de ações ordinárias e extraordinárias, sempre complementando as interpretações cartográficas com a história extraída dos documentos.

Dentre várias características sobre a forma inicial da Vila de São Paulo de Piratininga, o autor buscou evidências tangíveis, inclusive nos mapas coloniais, do que teria sido uma muralha localizada às margens do Rio Tamanduateí (Figura 3). Ao descrever esse elemento, Reis (2004, p. 23) dialoga com a hipótese de que estruturas anteriores podem ter condicionado, pela continuidade, as estruturas subsequentes: 'Assim, séculos depois de derrubados os muros de uma vila ou cidade, era possível reconhecer seu antigo percurso, porque seu desenho ficava fixado, pelo menos em parte, no traçado das ruas. Estas formavam em planta um polígono, encadeando-se umas às outras, como uma linha contínua, quase sem interrupções. As portas também deixavam sinais importantes na paisagem. Para saber sua localização, devemos lembrar que deviam se situar nos limites da vila, abrindo para os principais caminhos de acesso (...).
São esses alguns tipos de sinais que devemos procurar nas plantas antigas da vila e depois cidade de São Paulo, para conhecer o percurso de seus muros'.

Em 'Quadro da arquitetura no Brasil', Reis (2014[1970]) analisou as relações entre arquitetura e tipos de lote urbano. Em um dos argumentos desenvolvidos, o autor observou que há uma conexão direta e estreita entre a forma e dimensão dos lotes urbanos, e a forma e dimensão da arquitetura, havendo uma interdependência entre traçado urbano (bidimensional) e volume edificado (tridimensional). Esse fator é tão forte que o tecido urbano - 'a implantação da arquitetura urbana' - resulta da combinação das demandas sociais, econômicas, culturais e tecnológicas que incidem sobre o espaço privado, mas também dos fatores que determinam a forma do espaço público.

Reis (2014[1970], p. 16) entendeu com isso que, no Brasil, durante o século XIX, a relação arquitetura-lote entrou em descompasso, com a potência de transformação do lote em defasagem à da arquitetura. Naquele tempo, os então novos padrões da arquitetura eclética se adaptavam aos padrões formais dos lotes coloniais que lentamente (ou pouco) mudaram. As estruturas urbanas de fato só viriam a sofrer mudanças formais significativas durante o século XX: 'Como ressalva, apenas será de notar que a arquitetura é mais facilmente adaptável às modificações do plano econômico-social do que o lote urbano, pois as modificações deste exigem, em geral, uma alteração do próprio traçado urbano. Em decorrência, os sinais da evolução podem ser reconhecidos quase sempre - senão sempre em primeiro lugar no plano arquitetônico e só depois no urbanístico, onde são fruto de uma adaptação mais lenta. Essa defasagem explica algumas aparentes contradições, como, por exemplo, a utilização corrente de esquemas do século XIX em bairros novos das cidades brasileiras dos dias atuais, quando o seu emprego já vai sendo considerado como um arcaísmo em países mais desenvolvidos. (...) a arquitetura terá que aguardar a evolução dos modelos urbanísticos, para alcançar o pleno desenvolvimento das soluções arquitetônicas 


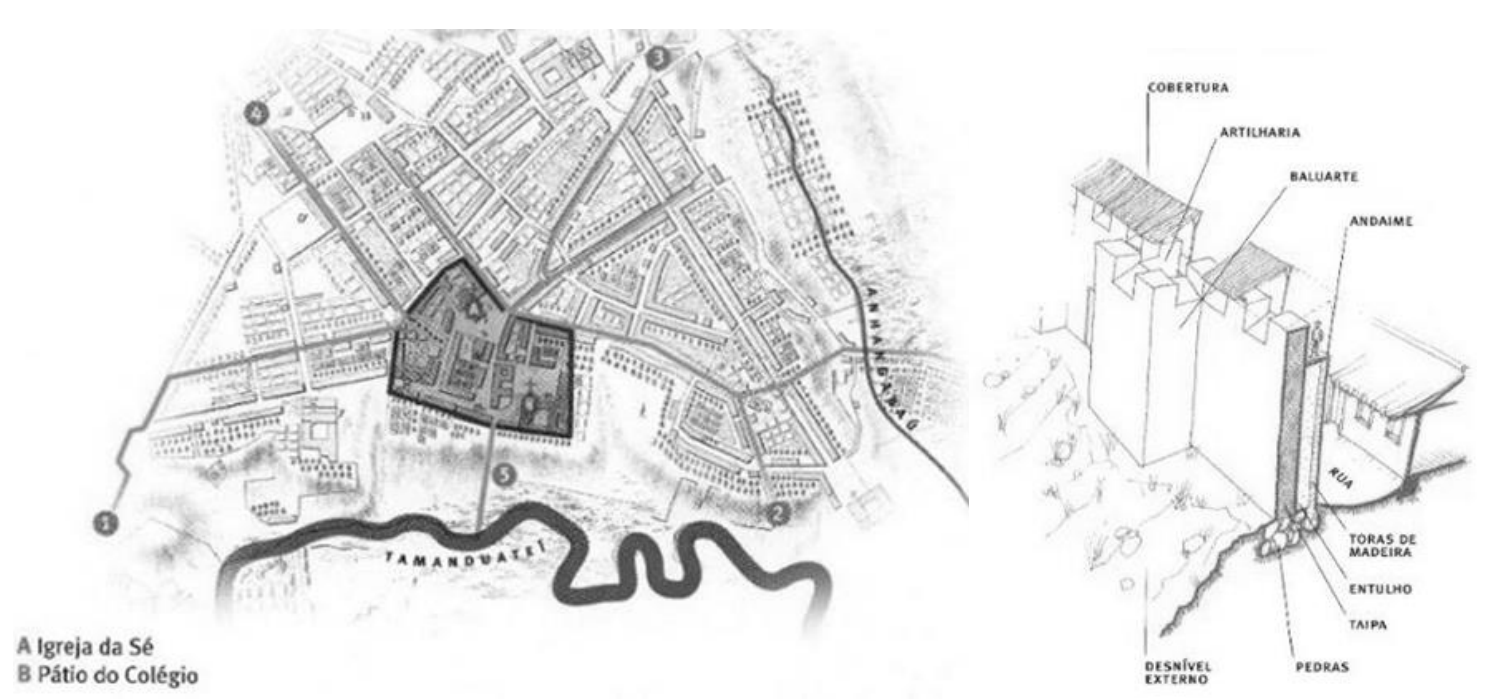

Figura 3. Estudos sobre o traçado hipotético das muralhas e caminhos de entrada e saída da Vila de São Paulo de Piratininga ( fonte: Reis, 2004, p. 20).

correspondentes'.

De modo geral estas análises com considerações morfológicas de ordem elementar colocam o traçado urbano como detentor e protagonista da memória do território porque esse conjunto bidimensional é o mais persistente no tempo.

Abreu, em 'Geografia histórica do Rio de Janeiro (1502-1700)', elaborou mapas hipotéticos do Rio de Janeiro do século XVI, inclusive com a indicação dos caminhos primitivos. $\mathrm{O}$ caráter hipotético da reconstituição é colocado pelo autor como alternativa de investigação histórica uma vez que a colina original do sítio carioca foi arrasada, a documentação cartográfica do período colonial do Rio de Janeiro não existe e as fontes documentais de períodos posteriores devem ser utilizadas com cautela. Como o autor mesmo diz, '(...) juntando peças de um quebra-cabeça (...)', foi possível se aproximar do Rio primitivo ' (...) ainda que saibamos que nunca seremos capazes de avistá-lo perfeitamente' (Abreu, 2010).

Segundo Abreu (2010), para assentar a cidade de São Sebastião, o português Mem de Sá relatou ao Rei ter escolhido uma colina. Essa opção, necessariamente, veio acompanhada da abertura de caminhos que the dessem acesso, interligando a parte alta e baixa da cidade. Amparado em pesquisa documental, o autor identificou três dos caminhos das primeiras décadas de vida da cidade: o caminho em direção a Piaçaba, conhecido como 'Ladeira da Misericórdia'; o 'Caminho do Poço do Porteiro' (século XVII), denominado 'Ladeira do Seminário', que se juntava na várzea a uma antiga trilha indígena; e, por fim, a 'Ladeira do Colégio' ou 'Ladeira do Carmo'. Em alguns trechos do livro, o autor tratou da persistência da forma do Caminho do Poço do Porteiro: 'Descendo a encosta em direção oposta à Ladeira da Misericórdia, esse caminho era o mais íngreme dos três e, ao que tudo indica, se juntava na várzea a uma antiga trilha indígena que, em seu trecho inicial, seguia o eixo da atual Rua Evaristo da Veiga (Abreu, 2010, p. 218).

Em se tratando da persistência de trilhas indígenas, desde o século XIX, pesquisadores brasileiros se detiveram sobre o estudo do Peabiru, um caminho sulamericano que conectava povoamentos, desde os Andes até o Oceano Atlântico, registrado pelos padres jesuítas tão logo chegaram ao Brasil, no século XVI. Teóricos contemporâneos acreditam que, com seus mais de $3.000 \mathrm{~km}$, esse tenha sido um caminho que passava por quatro países (Peru, Bolívia, Paraguai e Brasil) e que, nos limites do território brasileiro, percorreu as cidades de Foz do Iguaçu, Botucatu, Sorocaba e São Paulo - dentre outras cidades e Estados (Gonçalves, 1998; Holanda, 2014[1945]; Rocha Filho, 1994). 
Sobre o estudo dos fragmentos desse caminho, no trecho compreendido pelos limites da cidade de São Paulo, destacam-se as pesquisas de Holanda (1994[1957]), Rocha Filho (1994) e Gonçalves (1998), dentre outros. Holanda reconhece São Paulo como um nó de caminhos, identificando, por meio de pesquisa documental textual, diversos trajetos de andanças e expedições no período colonial brasileiro.

De modo geral, esses autores atribuíram, por hipótese, a existência desse caminho a uma função comercial estabelecida como intercâmbio entre povos indígenas que habitavam o litoral e o interior do continente, além do sentido criado pelos povos incas para dominação territorial e circulação de metais preciosos, como o ouro, desde Cusco (Peru) até o litoral atlântico. Sobre os aspectos materiais desse caminho, pesquisadores identificaram fragmentos que evidenciam sua existência em áreas vegetadas, rurais e mesmo dentro do tecido urbano, evidências estas de origem arqueológica, historiográfica e cartográfica: 'É plausível supor, sem dúvida, que, mesmo antes da conquista, certas trilhas indígenas fossem mais do que picadas intratáveis: no Brasil há o exemplo bem conhecido do Piabiru [sic], ou Caminho de São Tomé, largo de oito palmos, por onde nascia uma erva miúda que, dos dois lados, crescia até quase meia vara, e ainda quando queimassem os campos nascia sempre aquela erva e do mesmo modo (Holanda, 2014[1945], p. 40).

Em 'Caminhos e fronteiras', Holanda (1994[1957]), ao tratar da São Paulo do século XVII, faz referência ao Peabiru ao mesmo tempo em que destaca um sistema de estradas com rotas ligando o sertão à costa. Sobre os 'tênues e rudimentares' caminhos de índios, as trilhas de bandeirantes, '(...) que apenas seguiam caminhos já existentes (...)' em sua marcha a pé, o autor afirma: 'Da existência efetiva dessas vias já com caráter mais ou menos permanente, antes de iniciarse a colonização, nada autoriza a duvidar. E ainda hoje, o traçado de muitas estradas de ferro parece concordar, no essencial, com o dos velhos caminhos de índios e bandeirantes, sinal de que sua localização não seria caprichosa (Holanda, 1994[1957]), p. 26).

\section{O Eixo Maruípe}

$\mathrm{Na}$ tentativa de individualizar um objeto específico que pudesse ser estudado, na cidade de Vitória (Espírito Santo, Brasil), e que desse suporte a investigação da hipótese de um caso de persistência morfológica elementar, chegou-se por análise cartográfica a um conjunto de vias localizado na parte intermédia da ilha, denominado por Eixo Maruípe (Figura 4).

Por meio de análise cartográfica e documental, percorrendo os períodos históricos brasileiros da República, Império e Colônia foi possível identificar a existência de uma ligação terrestre entre o núcleo de povoamento inicial, em Vitória, seguindo na direção Norte, possivelmente oriundo do período colonial e que durante os séculos XVII e XVIII se estabilizou, pouco a pouco, por consequência de sua função como rota comercial. Entretanto, este não foi o único motivo de sua persistência.

As características topográficas locais também influenciaram na manutenção do eixo e do trajeto da via. Assim, a partir dos dados pesquisados, como um resultado parcial da pesquisa, constata-se a existência de três escalas de persistência morfológica: a escala do território, da cidade e da região.

Quanto à persistência na escala do território, o Eixo Maruípe é um vestígio material do que teria sido uma das estradas interprovinciais do Espírito Santo, aquela denominada Estrada Geral da Costa. Descrita nos documentos textuais do período imperial como estreita, sinuosa, que corria em paralelo ou junto ao mar, sem data definida de inauguração, quase natural, se estendia desde o Sul e continuava a se conectar com os principais núcleos litorâneos ao Norte. Numa comparação morfológica, amparada nos documentos encontrados e na qual são consideradas as linhas de talvegue da ilha, direção, inflexões, conclui-se que o Eixo Maruípe é correspondente à uma parte de um trecho da Estrada da Costa que passava por dentro da Ilha de Vitória. Portanto, o conjunto de vias que formam o Eixo Maruípe não foi uma criação da República, mas já existia no Império.

Entretanto, com o desenvolvimento das leituras, em algum momento da pesquisa, 


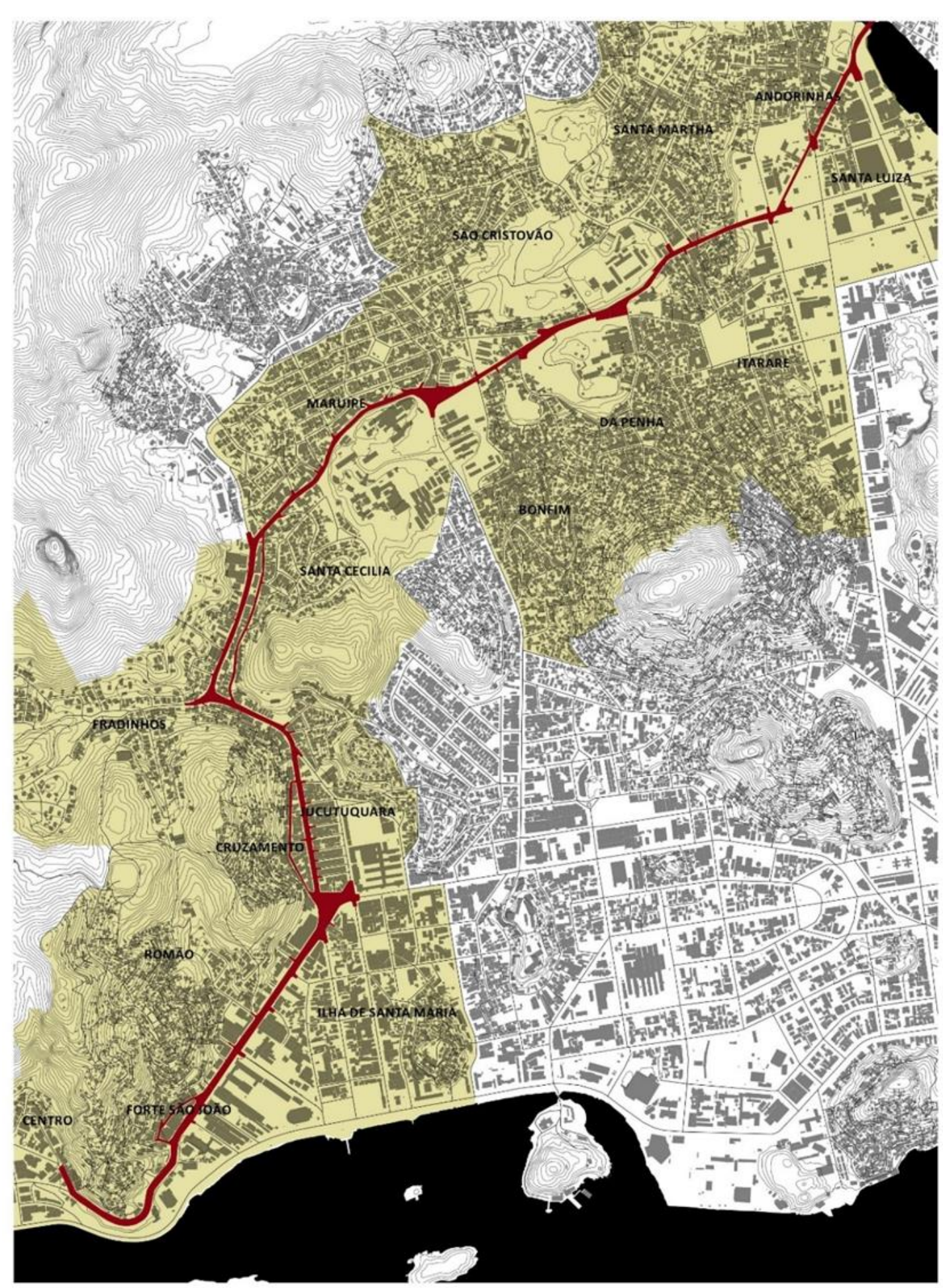

Eixo Maruipe

(1) $\quad \begin{array}{llll}0 & 250 & 500 & 750 \mathrm{~m}\end{array}$

_ eixos de logradouro —_ curvas de nivel

bairros

Eixo Maruipe
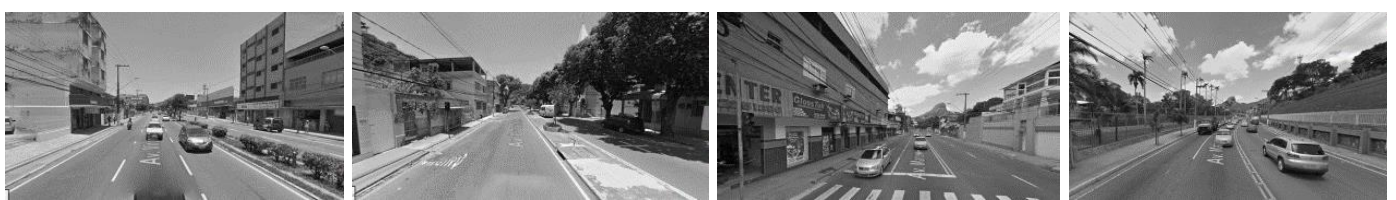

Figura 4. Trecho do município de Vitória com identificação do Eixo Maruípe. 
passou-se a acreditar que era possível retroceder no tempo ainda um pouco mais. Pelas descrições físicas desta estrada nos Relatórios e Mensagens dos Presidentes da Província do Espírito Santo não se percebia, como na descrição das demais estradas, indicativos sobre as tentativas para sua abertura, sucessos, fracassos... Pelo contrário, havia com frequência uma abordagem sobre a necessidade de melhorar, de investir, de pavimentar, de torná-lo um eixo carroçável.

$\mathrm{O}$ que parece semântica poderia ser $\mathrm{o}$ indício de uma persistência deste objeto na escala da cidade. Esta segunda escala de persistência ampara-se nas evidências de que existia, nos limites da ilha, caminhos indígenas entre as aldeias primitivas, que seguiam as linhas de talvegue em paralelo aos rios. Seguindo a direção Norte, a linha de talvegue mais evidente é justamente o encaminhamento do Eixo Maruípe, por entre os Morros São João, Romão, Cruzamento, Jucutuquara, Macaco, Engenharia.

Numa terceira escala de persistência, considerou-se o processo de urbanização da região Nordeste de Vitória por onde o Eixo Maruípe passa (Figura 5). Durante o século $\mathrm{XX}$, esta região composta basicamente por duas fazendas maiores - Maruípe e Jucutuquara - foi vendida, parcelada em loteamentos, doada parcialmente ao Governo. Aos poucos, através da ação de agentes do Estado, a outrora estrada foi passando a ser denominada rua ou avenida por meio de uma série de melhoramentos. A toponímia se apagou, mas não seu direcionamento ou sua materialidade. As transformações ocorrem? Sim e não. Concomitante às mudanças, o processo da permanência e persistência morfológica também ocorreu.

Durante a República, num processo de acumulação de intervenções de projetos urbanos o Eixo foi retificado, alargado, pavimentado e recebeu mobiliários urbanos de toda sorte, mas, continua acompanhando em paralelo as linhas topográficas e os cursos d'água (mesmo que ocultos), o nível de cota continua sem grandes alterações, a direção se mantém ligando o núcleo urbano central à Ponte da Passagem, e apesar da formação sucessiva do tecido urbano do entorno, a continuidade de trajeto não foi alterada.

\section{Considerações Finais}

A partir do que foi aqui brevemente exposto, registrou-se parte da discussão teórica, em estrutura aberta, sobre a longevidade dos elementos da forma urbana e a dessincronização dos ciclos de vida de edificações, lotes e ruas. Em relação à estagnação, pode-se afirmar que esta é resultante da mesma lógica econômica, política e social que atua na ocorrência dos processos de transformação, adição, adaptação (e por que não apagamento?), que, por sua vez, compõem algo maior que diz respeito à formação das estruturas e da materialidade da cidade.

Se as transformações foram protagonistas de parte dos estudos sobre a história da cidade, muitas vezes sendo vistas com encanto e nostalgia, a análise comparativa das plantas urbanas dá suporte à identificação das estruturas de longa duração que, apesar dos projetos e das ações de agentes públicos e privados, permaneceram. Elementos primitivos tão fortes que, a despeito das camadas acumulativas da história, quando se olha o território com um olhar atento, de alguma maneira, ainda estão lá.

Como questão complementar, a pesquisa bibliográfica realizada lançou-se foco sobre a persistência da rua. Entretanto, como tudo o que dura muito tempo, o espaço público não ultrapassou diversas camadas sem passar por deformações, intervenções, alterações. Entra aí a importância da teoria de Conzen que identifica os processos morfológicos de metamorfose da forma urbana, com destaque à persistência das formas herdadas e a argumentação de Lavedan. Compreende-se com isso o papel dos espaços públicos para a memória das cidades pois estes são mais duradouros do que os edifícios. Uma memória contida no 'chão da cidade' (Portas, 2005) que pode desvendar os elementos de atravessamento entre passado e futuro. 

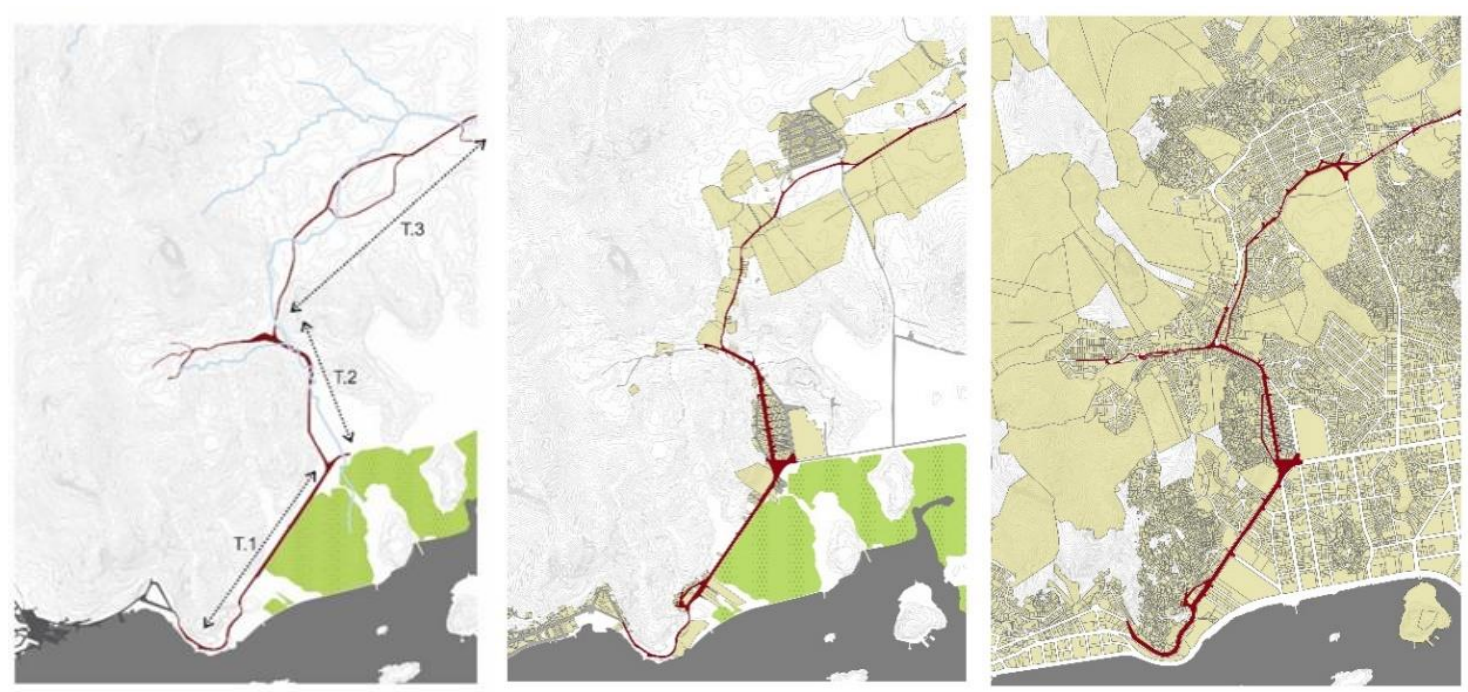

Figura 5. Plantas conjecturais dos anos de 1911, 1946 e 1979 de trecho do município de Vitória, com identificação em destaque para a direção de parte do Eixo Maruípe.

\section{Referências}

Abreu, M. de A. (2012) Geografia histórica do Rio de Janeiro 1502-1700 (Andrea Jakobsson Estúdio, Rio de Janeiro).

Conzen, M. R. G. (1960) Alnwick, Northumberland: a study in town plan analysis, Institute of British Geographers Publication 27 (George Philip, Londres).

Conzen, M. R. G. (2004) Thinking about urban form: papers on urban morphology (19321998), M. P. Conzen (ed.) (Peter Lang Publishers, Nova Iorque).

Dias Coelho, C. (org.) (2013) Cadernos de morfologia urbana: os elementos urbanos (Argumentum, Lisboa).

Dias Coelho, C. (org.) (2014) Cadernos de morfologia urbana: o tempo e a forma (Argumentum, Lisboa).

Didi-Huberman, G. (2011) Sobrevivência dos vaga-lumes (Editora UFMG, Belo Horizonte).

Gonçalves, D. I. (1998) 'O Peabiru: uma trilha indígena cruzando São Paulo', Cadernos de Pesquisa do LAP-USP-FAU 24.

Grudet, I. (2007) 'L'historien Pierre Lavedan et les transformations de l'urbanisme en France (1919-1955)', Espaces et Sociétés 130, 41-55.

Holanda, S. B. de (1994[1957]) Caminhos $e$ fronteiras (Companhia das Letras, São Paulo).

Holanda, S. B. de (2014[1945]) Capítulos da expansão paulista (Companhia das Letras, São Paulo).
Kostof, S. (1991-2009) The city shaped: urban patterns and meanings through History (Thames \& Hudson, Londres).

Lavedan, P. (1926) Qu'est-ce que l'urbanisme? (Laurens, Paris).

Morris, A. E. J. (1979) Historia de la forma urbana (G. Gili, Barcelona).

Pereira Costa, S. A. e Gimmler Neto, M. M. (2015) Fundamentos de Morfologia Urbana (C/Arte, Belo Horizonte).

Pinon, P. (2008) 'Défense et illustration de la loi de persistance du plan: le problème de la survivance du tracé des rues dans les villes françaises d'origine antique', em Ballet, P., Dieudonné-Glad N. e Saliou, S. (org.) La rue dans l'Antiquité: définition, aménagement, devenir (Presses Universitaires de Rennes, Paris) 129-40.

Portas, N. (2005) Os tempos das formas: a cidade feita e refeita (Universidade do Minho, Guimarães)

Reis, N. G. (2014 [1970]) Quadro da arquitetura no Brasil (Perspectiva, São Paulo).

Reis, N. G. (2004) São Paulo: vila, cidade, metrópole (Ministério da Cultura, São Paulo).

Rocha Filho, G. N. da (1994) Os caminhos quinhentistas de São Paulo (http://historiadesaopaulo.com.br/) consultado em 10 agosto de 2017.

Waisman, M. (2013) O interior da história: historiografia arquitetônica para uso de latinoamericanos (Perspectiva, São Paulo). 


\title{
Tradução do título, resumo e palavras-chave
}

The longevity of the elements of urban form

\begin{abstract}
This paper, which is based on a chapter of a PhD thesis, is in two parts. The first part corresponds to the understanding of the notion of morphological processes, having as a guiding thread the work developed by M. R. G. Conzen, who considered the actions of transformation, addition, adaptation and stagnation. In the second part, motivated by the PhD research, attention is given to the process of stagnation with emphasis in the persistence of the urban elements, including studies of this nature on cities in Europe and Latin American as well as the case study developed in the thesis. The purpose of the bibliographical research was to collect theoretical and practical answers for the study of the persistence of the street, considering an ordinary, active city where the process of transformation is continuous, given by material, human or temporal action, without external interference of an exceptional nature.
\end{abstract}

\section{Rede Lusófona de Morfologia Urbana (PNUM), 2017-2018}

O presente relatório descreve a atividade recente de 'Rede Lusófona de Morfologia Urbana' (Portuguese-language Network of Urban Morphology / PNUM). O meu segundo mandato como presidente do PNUM (depois de um primeiro mandato entre 2011 e 2014) começou em Agosto de 2017 no final da conferência de Vitória, no Brasil, com um sentido agradecimento à nossa anterior presidente Teresa Marat-Mendes (ISCTE - Instituto Universitário de Lisboa). Nessa mesma conferência Staël de Alvarenga Pereira Costa (Universidade Federal de Minas Gerais) foi eleita vice-presidente do PNUM. David Viana (Nottingham Trent University), Eneida Mendonça (Universidade Federal do Espírito Santo) e Karin Schwabe Meneguetti (Universidade Estadual de Maringá) foram eleitos membros do Conselho Científico.

Depois de um ano no Brasil, a conferência anual regressou a Portugal. O PNUM 2018 teve lugar na Faculdade de Arquitectura da Universidade do Porto, de 18 a 20 de Julho, sob coordenação de Teresa Calix (Universidade do Porto). A conferência centrou-se na transformação do território e estruturou-se em três partes. A primeira parte abordou o tema das formas urbanas e incluiu debate sobre: ferramentas, técnicas e métodos; elementos e padrões; espaços privados e coletivos; e sistemas, redes e paisagens. A segunda parte centrou-se nos processos, discutindo temáticas como: atores e participação; regulação e execução; e regeneração urbana, património e herança. Por fim, a terceira parte focou-se nos desígnios: teorias e utopias; novos paradigmas e desafios; e práticas e didáticas de ensino.

Movendo-se em sentido contrário, da Europa para a América do Sul, o workshop da Rede
Lusófona deste ano teve lugar em Maringá, no estado Brasileiro do Paraná. O workshop realizou-se na Universidade Estadual de Maringá, entre 27 e 29 de Setembro, sob a coordenação de Renato Leão Rego, Karin Schwabe Meneguetti e Gislaine Beloto (Universidade Estadual de Maringá). O workshop centrou-se nos atuais processos de crescimento desta cidade planeada (incluindo também as cidades de Sarandi e Paiçandu, a Sul), prestando particular atenção à relação entre morfologia urbana e ecologia.

A 'Revista de Morfologia Urbana' está no seu sexto ano de publicação. Nos últimos cinco anos incluiu textos de 90 autores. O anterior número da revista, incluiu três artigos e duas 'perspetivas' sobre: a combinação de métodos para descrição e explicação da forma urbana; a exploração de geografias temporais de encontros sociais; o processo de produção e transformação da forma urbana em cidades costeiras brasileiras; a escola Catalã de morfologia urbana, baseada no trabalho de Manuel Solà-Morales i Rubió; e, por fim, sobre ideias e sobre a sua influência na forma urbana (numa perspetiva histórica).

A conferência anual, o workshop anual e a revista são os três elementos fundamentais da atividade da Rede Lusófona. Em cada ano, oferecem a quem neles participa um palco para debater e aplicar as principais teorias, conceitos e métodos para a descrição, explicação e prescrição da forma física das cidades.

Vitor Oliveira, CITTA - Centro de Investigação do Território, Transportes e Ambiente, Faculdade de Engenharia, Universidade do Porto, Rua Roberto Frias 4200-465 Porto, Portugal. E-mail: vitorm@fe.up.pt 